\title{
Plasma $A \beta 42$ and $A \beta 40$ as markers of cognitive change in follow-up: a prospective, longitudinal, population-based cohort study
}

\author{
T T Seppälä, S-K Herukka, T Hänninen, S Tervo, M Hallikainen, H Soininen, T Pirttilä
}

Department of Neurology, Kuopio University Hospital, University of Eastern Finland, Kuopio, Finland

\section{Correspondence to} Dr Tuula Pirttilä, Department of Neurology, Bldg 5, Kuopio University Hospital POB 1777, 70211, Kuopio, Finland; tuula.pirttila@kuh.fi

Received 13 January 2010 Accepted 22 January 2010 Published Online First 16 May 2010

\section{UNLOCKID}

This paper is freely available online under the BMJ Journals unlocked scheme, see http:// jnnp.bmj.com/site/about/ unlocked.xhtml

\begin{abstract}
Background Single measurements of plasma $A \beta$ are not useful in the diagnostics of Alzheimer's disease (AD). However, changes in plasma $A \beta$ levels during repeated testing may be helpful in the prediction and evaluation of progression of the incipient $A D$ or mild cognitive impairment.
\end{abstract}

Objective To examine the relation of baseline and serial plasma $A \beta$ levels to cognitive change in follow-up. Methods 269 subjects (52 cognitively impaired and 217 controls) from a population-based cohort were clinically followed up from 3 to 6 years. Serial plasma samples were available from 70 subjects who were followed up for 3 years and 43 subjects followed for 6 years. The plasma $A \beta$ levels were measured using ELISA.

Results Subjects who declined cognitively during the follow-up had lower levels of plasma $A \beta 42$ at the baseline. Plasma $A \beta 42$ and the $A \beta 42 / A \beta 40$ ratio decreased $(-2.4 \mathrm{pg} / \mathrm{ml}$ for $A \beta 42$ in 6 years) in those who declined in follow-up, whereas $A \beta 42$ and the $A \beta 42 /$ $A \beta 40$ ratio increased in the subjects who remained cognitively stable or improved in follow-up. Subjects using acetylsalicylic acid, dipyridamole, antidiabetic or anticoagulant drugs as well as subjects with coronary heart disease had higher levels of $A \beta 40$.

Conclusions Low or decreasing plasma $A \beta 42$ during the follow-up is associated with cognitive decline. Serial measurement of plasma $A \beta 42$ may be useful in the detection of the subjects who are at risk for cognitive decline.

\section{INTRODUCTION}

Alzheimer's disease (AD) is the most common cause of dementia. At present, its diagnosis is based on clinical criteria and the exclusion of other causes. However, objective biomarkers for the early diagnosis and monitoring of the disease process are clearly needed because symptomatic treatments are available, and disease-modifying drugs are already in phase III trials. The presence of amyloid $\beta$ deposition in senile plaques is one pathological hallmark of Alzheimer's disease $(\mathrm{AD})$ together with neurofibrillar tangles. ${ }^{1}$ The amyloid $\beta$ is a peptide secreted by neurons ${ }^{1}$ and platelets, ${ }^{2}$ derived from amyloid precursor protein APP via the activity of proteases $\beta$ and $\gamma$ secretase. $^{3}$ Most of the $\mathrm{A} \beta$ deposited in the brain is composed of 42 amino acids (A $A 42$ ) form. ${ }^{4} \mathrm{~A} \beta 42$ has also been shown to be first amyloid form to accumulate with $A \beta 40$ being deposited later in the process of $\mathrm{AD}$ pathogenesis. ${ }^{5}$ The level of AB42 in cerebrospinal fluid (CSF) is reduced in patients with mild cognitive impairment (MCI) and $\mathrm{AD},{ }^{67}$ and a combination test of CSF
A $\beta 42$ and $\tau$ or phospho-tau has been claimed to be helpful in the early diagnosis of $\mathrm{AD} .^{8}$

$A \beta$ is present in plasma, but it is still unknown whether it originates from peripheral sources or from the brain. In Tg2576 transgenic mouse, plasma A $\beta$ levels decline in parallel with their increasing accumulation in the brain. ${ }^{9}$ Since $A \beta$ can be transported bidirectionally across the blood-brain barrier, it has been hypothesised that there may be an equilibrium between CSF and plasma pools of $A \beta .^{10}{ }^{11}$ Seeing that it is well established that CSF A $\beta 42$ levels decrease in conjunction with the cognitive decline, it has been postulated that plasma $A \beta 42$ may decrease similarly. ${ }^{12}$ If so, plasma $A \beta$ would offer a straightforward, non-invasive and economical biomarker for $\mathrm{AD}$. However, patients with known mutations in chromosome 21 causing early-onset familial $\mathrm{AD}$ as well as patients with trisomy 21 have increased plasma AB42 levels which are detectable before the onset of the symptoms of dementia. ${ }^{13}{ }^{14}$ Also, the first-degree relatives of late-onset $\mathrm{AD}$ patients exhibit elevated $A \beta$ levels measured in plasma. ${ }^{15}$

Previous studies have suggested that the levels of plasma $A \beta 40$ are increased before the onset of sporadic $\mathrm{AD} .{ }^{16}{ }^{17}$ However, one recent study concluded that low plasma $A \beta 40$ level predicted $A D$ in older men. ${ }^{18}$ Other studies have found elevated $\mathrm{A} \beta 42$ levels in patients who later develop dementia, ${ }^{19}$ particularly in MCI amnestic type. (aMCI) ${ }^{20}$ Finally, several studies have not been able to detect any significant difference of $A \beta$ levels between $A D$ converters and cognitively stable controls. ${ }^{21} 22$

It seems that a single measurement of plasma $A \beta$ is not useful, whereas the change in plasma $A \beta$ levels observed in repeated testing may be of help in the prediction and evaluation of progression of incipient $\mathrm{AD}$ or $\mathrm{MCI}^{23}$ However, only a limited number of longitudinal studies have been performed. ${ }^{24-26}$ Our aim was to examine whether the change in plasma $A \beta$ levels during follow-up would be more predictive of cognitive decline than straightforward baseline plasma $\mathrm{A} \beta$ levels in a population-based cohort of $\mathrm{MCI}$ and cognitively intact controls.

\section{SUBJECTS AND METHODS Subjects}

Study subjects were participants in the populationbased study ( $\mathrm{n}=806$, aged $60-76$ years) examining the risk factors and predictors of dementia in older people $^{2728}$ (table 1). At baseline (years 1997-1998), 52 subjects were cognitively impaired (Clinical Dementia rating (CDR) $0.5 \mathrm{n}=51$ and CDR $1 \mathrm{n}=1$ ). Group 1 of this study included all of the cognitively impaired subjects from the original cohort who 
Table 1 Baseline demographic information of the subjects

\begin{tabular}{llllll}
\hline & $\begin{array}{l}\text { Population-based } \\
\text { cohort }\end{array}$ & $\begin{array}{l}\text { Group 1 (cognitive } \\
\text { follow-up) }\end{array}$ & \multicolumn{2}{l}{$\begin{array}{l}\text { Group 2 (plasma } \\
\text { follow-up) }\end{array}$} \\
\hline $\mathrm{n}$ & 806 & 269 & 70 & \\
Age & $68(60-76)$ & $70(60-77)$ & $\mathrm{p}>0.1$ & $71(61-77)$ & $\mathrm{p}>0.1$ \\
Men/women & $321 / 48547 \% / 53 \%$ & $121 / 14845 \% / 55 \%$ & $\mathrm{p}>0.1$ & $25 / 4536 \% / 64 \%$ & $\mathrm{p}>0.1$ \\
APOE $\in 4-/+$ & $414 / 207^{*} 67 \% / 33 \%$ & $169 / 99 \dagger 63 \% / 37 \%$ & $\mathrm{p}>0.1$ & $37 / 3353 \% / 47 \%$ & $\mathrm{p}>0.05$ \\
Mini-Mental State Examination & $26(7-30)$ & $27(13-30)$ & & $26(17-30)$ & \\
$\mathrm{CDR}=0$ & 731 & 217 & 59 & \\
$\mathrm{CDR}=0.5$ & 70 & 51 & 0 & 11 \\
$\mathrm{CDR}=1 \neq$ & 3 & 1 & 0 & \\
\hline
\end{tabular}

Data are given as median values (range) or as number of subjects with the percentage of all subjects in the group.

*APOE data missing from 185 subjects.

†APOE data missing from one subject.

$\neq$ One subject had CDR 2. Data missing from one subject.

CDR, Clinical Dementia rating.

provided a plasma sample $(n=52)$. For each of them, we randomly selected $4-5$ cognitively unimpaired $(n=217)$ age- and sex-matched controls from the same cohort. These subjects were clinically re-evaluated after 3 years $(n=197)$ and 6 years $(n=60)$.

The longitudinal marker group (group 2) included 70 subjects of the original cohort of 269 subjects who provided a 3-year follow-up plasma sample and 43 of them a 6-year follow-up sample. Group 2 included 11 cognitively impaired (at baseline) non-demented subjects (CDR 0.5) who provided at least one follow-up plasma sample and 59 cognitively intact (at baseline) age- and sex-matched controls with at least one follow-up plasma sample (figure 1). Drop-outs occurred mainly due to a refusal of the participants to continue the study. Written informed consent was obtained from all the subjects, and the study was approved by the local Ethical Committee.

\section{Clinical evaluation}

The evaluation included a structured detailed interview including demographic information, medical history, medication, smoking habits and alcohol consumption, and a subjective assessment of memory disturbances and depression. The evaluation also included clinical examination as well as an assessment of cognitive impairment by applying the CDR and using a battery of neuropsychological tests: Memory: Visual Reproduction Test from Wechsler Memory Scale, ${ }^{29}$ Word List Recall from the CERAD Neuropsychological Assessment Battery, ${ }^{30}$ Logical Memory Test from Wechsler Memory Scale-Revised, ${ }^{31}$ NYU Paragraph Recall, ${ }^{32}$ Delayed Recall of the Constructional Praxis from CERAD; ${ }^{30}$ Language: vocabulary subtest from the

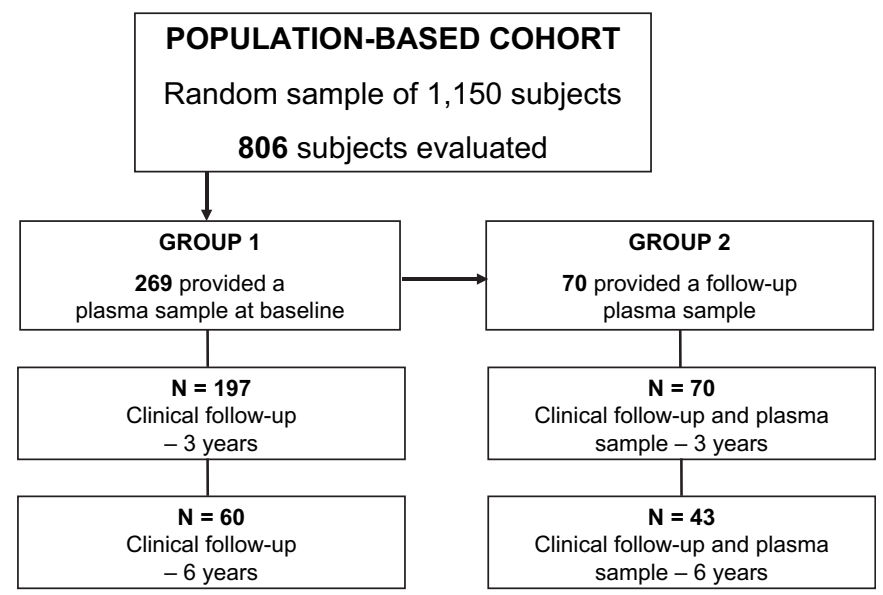

Figure 1 Formation of the study population.
Wechsler Adult Intelligence Scale-Revised, ${ }^{33}$ Abbreviated (15 items) Boston Naming Test; ${ }^{34}$ Attention and executive function: Trail Making Test ${ }^{35}$ parts A and B, Verbal Fluency Test; ${ }^{36} 37$ Visuospatial skills: Block Design from the WAIS-R, ${ }^{33}$ Constructional Praxis from CERAD; ${ }^{30}$ Global functioning: MiniMental State Examination ${ }^{38}$ (MMSE) Clock Drawing Test. ${ }^{30}$

Cognitive decline was defined by the CDR change from 0 to 0.5 or 0.5 to 1 .

\section{Measurement of $A \boldsymbol{\beta} 40$ and $A \boldsymbol{\beta} 42$}

The 269 baseline samples (group 1) were measured in year 2002-2003. After completing the 6-year follow-up, we reanalysed the baseline samples of 70 subjects (group 2) together with their follow-up samples in year 2006-2007 (group 2).

A venous blood sample was obtained into heparin tubes, and plasma was separated using standard methods. The samples were aliquotted and stored in polypropylene tubes at $-70^{\circ} \mathrm{C}$ until analyses. A $\beta 40$ was measured by the ELISA method modified from a well-established method. ${ }^{16}$ The capture antibody was $6 \mathrm{E} 10$ (Sigma, St Louis, Missouri), and the detection antibody was a biotin-labelled G2-10 antibody (The Genetics Company, Schlieren, Switzerland). The synthetic $A \beta_{1-40}$ peptide (Bachem, Bubendorf, Switzerland) was used as the standard. Before the analyses, $0.05 \%$ Tween $20-0.5 \%$ BSA was added to the samples. A $\beta 42$ was measured by a high-sensitivity method of a commercially available ELISA (Innogenetics, Gent, Belgium) which we modified to be suitable for the measurements of concentrations higher than $7 \mathrm{pg} / \mathrm{ml}$. Before the analyses, $0.5 \mathrm{M}$ guanidine chloride was added to the standards and samples. The detergents were used to avoid coagulation of samples and to release $A \beta$ peptides from plasma proteins.

In a longitudinal analysis, baseline and follow-up samples from one individual were placed on the same plate to prevent interassay variation. Thus, we measured baseline samples from 70 subjects twice (4 years apart). The absolute concentrations differed between these two measurements; median level for $\mathrm{A} \beta 40174.5$ (year 2003) and $198 \mathrm{pg} / \mathrm{ml}$ (74) (year 2007), and A 34217 (year 2003) and 49 pg/ml (110) (year 2007). However, there was a moderately good correlation between these measurements $(A \beta 40 \mathrm{r}=0.674, \mathrm{p}<0.001$ and $\mathrm{A} \beta 42 \mathrm{r}=0.824$, $p<0.001)$. The correlation figure is presented in the supplemental data (available at http://www.jnnp.com).

The interassay variation for the A $\beta 40$ assay was $23.8 \%$ and for the A $\beta 42$ assay $19.1 \%$. The inter-CVs were measured using reference samples of medium concentration $(\sim 250 \mathrm{pg} / \mathrm{ml}$ for $\mathrm{A} \beta 40$ and $\sim 400 \mathrm{pg} / \mathrm{ml}$ for $\mathrm{A} \beta 42)$. The intra-assay variations for A $\beta 40$ were $0.71 \%$ for high $(\sim 1200 \mathrm{pg} / \mathrm{ml}), 0.95 \%$ for medium and $5.9 \%$ for low concentrations $(\sim 150 \mathrm{pg} / \mathrm{ml})$. The intra-assay 
CVs (median) for A $\beta 42$ were 1.6\% ( 1000 pg/ml), 2.5\% and $9.8 \%(\sim 15 \mathrm{pg} / \mathrm{ml})$, respectively.

\section{APOE genotyping}

The APOE allele genotyping was done by a PCR-based method. ${ }^{39}$ The subjects were subdivided into the APOE $\in 4$ negative and APOE $\epsilon 4$ positive subjects.

\section{Statistics}

The statistical analyses were conducted using SPSS for Windows release 14.0.1 (SPSS, Chicago, Illinois). Due to the non-normal distribution of data, Kruskal Wallis, Mann-Whitney $U$ and Spearman correlation tests were used. The categorical data were analysed by the $\chi^{2}$ test. The ORs for cognitive decline of patients in different groups were calculated by logistic regression analysis. We fitted a linear regression slope by Microsoft Excel to analyse the alteration trend of $A \beta$ levels.

\section{RESULTS}

Table 1 presents the demographic information about the subjects. The baseline $A \beta 40$ and $A \beta 42$ levels of 269 individuals were generally low, although some subjects exhibited extremely high A $\beta 42$ levels. The limit for the 90th percentile was $101 \mathrm{pg} /$ $\mathrm{ml}$, but the highest measured level was $1341 \mathrm{pg} / \mathrm{ml}$. The A $\beta 40$ levels showed a weak correlation with age $(r=0.186, p=0.002)$, but this was not the case with the $A \beta 42$ levels. There were no differences in $A \beta 40$ and $A \beta 42$ levels between the sexes or between the APOE $\epsilon 4$ carriers and non-carriers. A $\beta 42$ levels did not correlate with $A \beta 40$ concentrations.

\section{Baseline $A \beta$ levels and cognitive decline during the follow-up}

No significant differences were found in plasma $A \beta 40, A \beta 42$ or the $A \beta 42 / A \beta 40$ ratio between cognitively impaired $(n=52)$ and cognitively intact subjects $(n=217)$ at baseline.

However, 197 of these subjects were clinically assessed after 3 years, and 60 were clinically assessed after 6 years. The baseline A $\beta 42$ levels were significantly lower in the subjects who showed cognitive decline after 3 years of follow-up (cognitively stable, $\mathrm{n}=147: 19 \mathrm{pg} / \mathrm{ml}$ (0-1341), cognitive decline, $\mathrm{n}=50: 12 \mathrm{pg} / \mathrm{ml}$ (0-276), $p=0.001)$. Baseline $A \beta 42$ levels were also lower in subjects who had declined cognitively after 6 years $(10 \mathrm{pg} / \mathrm{ml}$, $\mathrm{n}=36$ ) compared with those who remained cognitively stable (18 pg/ml, $\mathrm{n}=24), \mathrm{p}=0.013$.

Subjects who had baseline A $\beta 42$ levels in the lowest quartile displayed an OR of 3.12 (95\% CI 1.25 to $7.79, p=0.015$ ) for cognitive decline after 3 years and 4.77 (95\% CI 1.14 to 19.98 , $\mathrm{p}=0.033$ ) after 6 years in comparison with subjects who had A $\beta 42$ levels in the highest quartile. Similarly, subjects who had an $A \beta 42 / A \beta 40$ ratio in the lowest quartile had an OR of 3.26 (1.31 to 8.11, $\mathrm{p}=0.011$ ) for cognitive decline after 3 years and 8.40 (1.83 to 83.568, $\mathrm{p}=0.006$ ) after 6 years of follow-up when compared with the subjects in the highest quartile.

\section{Relationship between changing plasma $A \beta$ levels and cognitive decline}

The follow-up plasma samples were available from 70 subjects after 3 years and 43 subjects after 6 years of follow-up. The median levels of $A \beta 42$ did not change or decreased in subjects with cognitive decline $(n=27$ after 3 years and $n=14$ after 6 years), whereas they increased in those who remained cognitively stable (table 2 ). No statistically significant changes were found in $A \beta 40$ levels. The $A \beta 42 / A \beta 40$ ratio decreased significantly in the subjects who experienced a cognitive decline.

A trend analysis was undertaken by calculating a slope for each subject, and this was used to assess the change of $A \beta 42$ between cognitively stable and cognitively declining subjects. During the follow-up of 3-6 years, the cognition of 28 out of the total 70 subjects had declined, and there was a decreasing trend in the level of $A \beta 42$ in 24 subjects during the follow-up. The $A \beta 42$ level remained the same in the declining subjects and increased in the cognitively stable subjects $(0.0$ (4.9) pg/ml/year and 2.1 (21) $\mathrm{pg} / \mathrm{ml} /$ year; $\mathrm{p}=0.009$ for slope difference). The corresponding changes of $A \beta 42 / A \beta 40$ ratio were also significant (0.0 (0.029) per year and $0.0036(0.055)$ per year; $p=0.02$ for slope difference).

\section{Plasma $A \boldsymbol{\beta}$ and general health}

Table 3 shows the relationship between medication as well as certain diseases on the plasma $A \beta$ levels. The $A \beta 40$ levels were not associated with the use of lipid-lowering drugs or nonsteroidal anti-inflammatory drugs (NSAIDs) at baseline. Hormone-replacement therapy was not related to $A \beta$ values in women. The A $\beta 40$ levels were higher in those subjects using acetylsalicylic acid (ASA) $(n=62, p=0.004)$ or dipyridamole $(n=12, p=0.017)$. The $A \beta 40$ values were lowest in subjects using neither of the drugs, intermediate in subjects using either ASA or dipyridamole and highest in the subjects taking both drugs. The A $\beta 40$ levels were also higher in subjects using insulin alone $(\mathrm{n}=5, \mathrm{p}=0.009)$ or insulin in combination with oral antidiabetic drugs $(n=13, p=0.003)$. The $A \beta 42$ levels were not associated with the use of any of the drugs. Coronary heart disease was associated with a high plasma $A \beta 40$ level $(p=0.035)$. There was

Table 2 Cognition and changes of $A \beta$ between baseline and follow-ups in subjects

\begin{tabular}{|c|c|c|c|c|}
\hline Baseline & \multicolumn{2}{|c|}{ Cognitively healthy } & \multicolumn{2}{|c|}{ Cognitively impaired } \\
\hline $\mathrm{N}$ & \multicolumn{2}{|l|}{59} & \multicolumn{2}{|l|}{11} \\
\hline$A \beta 40$ & \multicolumn{2}{|l|}{$195(88)$} & \multicolumn{2}{|l|}{$201(60)$} \\
\hline$A \beta 42$ & \multicolumn{2}{|l|}{$50(121)$} & \multicolumn{2}{|l|}{$46(92)$} \\
\hline \multirow[t]{2}{*}{$A \beta 42 / A \beta 40$} & \multicolumn{2}{|c|}{$0.236(0.464)$} & \multicolumn{2}{|l|}{$0.291(0.487)$} \\
\hline & \multicolumn{2}{|c|}{ Cognitively stable or improved } & \multicolumn{2}{|l|}{ Cognitive decline } \\
\hline Follow-up & 3 years & 6 years & 3 years & 6 years \\
\hline $\mathrm{N}$ & $43 \dagger$ & $29 \neq$ & 27 & 14 \\
\hline Change of $A \beta 40$ & $18(55)$ & $33(45)$ & $21(24)$ & $33(75)$ \\
\hline Change of $A \beta 42$ & $3.7(29)$ & $12(54)$ & $0.0(14)^{*}$ & $-2.4(50)^{*}$ \\
\hline Change of $A \beta 42 / A \beta 40$ & $0.0093(0.169)$ & $0.0166(0.451)$ & $-0.0027(0.084)^{*}$ & $-0.0486(0.251)^{*}$ \\
\hline
\end{tabular}

Data are given as medians (IOR). The values of $p$ reflect the significance against the cognitively stable subgroup

* $p<0.05$ against 'stable or improved.'

†A $\beta$ data of one subject is from a plasma sample of 4 years of follow-up.

$\neq$ Cognition data of two subjects is from the previous year. 
Table 3 Relation of $A \beta 40$ level to medication at baseline

\begin{tabular}{llllll}
\hline & Group $\mathbf{1}$ & & \multicolumn{1}{c}{$\mathbf{p g} / \mathbf{m l}$} & $\mathbf{p g} / \mathbf{m l}$ \\
$\mathbf{n}$ & $\mathbf{A} \mathbf{3 4 0}$ & & Users & Non-users \\
\hline Sex, female & 148 & - & & & \\
Smoking & 21 & - & & & \\
Coronary heart disease & 61 & $\uparrow$ & $\mathrm{p}=0.035$ & $188(105-360)$ & $176(0-780)$ \\
Diabetes & 22 & - & & & \\
Anticoagulants & 16 & $\uparrow$ & $\mathrm{p}=0.038$ & $198(144-360)$ & $176(0-780)$ \\
Non-steroidal & 22 & - & & & \\
anti-inflammatory drugs & & & & & \\
Acetylsalicylic acid & 62 & $\uparrow$ & $\mathrm{p}=0.004$ & $194(0-278)$ & $175(0-780)$ \\
Dipyridamole & 12 & $\uparrow$ & $\mathrm{p}=0.016$ & $208(156-278)$ & $176(0-780)$ \\
Antidiabetics* & 13 & $\uparrow$ & $\mathrm{p}=0.003$ & $219(161-426)$ & $179(0-780)$ \\
Lipid-lowering agents & 24 & - & & & \\
\hline
\end{tabular}

*Insulin and oral antidiabetics.

no statistically significant difference in medication use between the cognitively stable and the cognitive decliners.

\section{DISCUSSION}

Our results indicated that low or decreasing plasma $A \beta 42$ levels and $A \beta 42 / A \beta 40$ ratio were related with cognitive decline during the follow-up. Moreover, a possible age-related increase in plasma A $\beta 42$ levels in serial measurements was associated with stable cognitive performance.

We found no differences in plasma $A \beta$ levels between cognitively intact and impaired subjects in the cross-sectional analysis at baseline. Previous cross-sectional studies comparing plasma A $\beta$ levels in patients with sporadic $\mathrm{AD}$ and controls have reported contradictory results. Elevations of plasma $A \beta 40^{16}$ or $A \beta 42^{19}$ have been described, whereas other studies have found no differences between $\mathrm{AD}$ and controls. ${ }^{21}$ One recent study found increased levels of plasma $\mathrm{A} \beta 42$ in women with amnestic MCI compared with healthy controls or affected men. ${ }^{40}$ However, low A $\beta 42$ levels at baseline were associated with a cognitive decline occurring during the follow-up. In line with our results, a recent study detected an association between a low $A \beta 42 / \mathrm{A} \beta 40$ ratio and cognitive decline. ${ }^{12}$ Respectively, a prospective three-city study of 257 dementia patients found an association of high $\mathrm{A} \beta 42 / \mathrm{A} \beta 40$ ratio with a lower risk of dementia in follow-up. ${ }^{41}$ Another population-based case-cohort study claimed that individuals with a combination of low $A \beta 42$ and high $A \beta 40$ measured from plasma at baseline had more than a 10 -fold risk of dementia but found no association between the $A \beta 42$ or $A \beta 40$ levels alone with cognitive decline. ${ }^{17}$ Other studies have reported different results. The VITA study found no association between baseline $A \beta$ levels and cognitive decline during the follow-up. Other studies have found elevated concentrations of $A \beta 42$ at the baseline in subjects who developed $\mathrm{AD}$ during the follow-up, ${ }^{19} 42$ although plasma $A \beta$ levels were not associated with $\mathrm{AD}$ in the fully adjusted multivariate model. ${ }^{42}$

Differences in study cohorts, for example timing with respect to cognitive decline, assessment of cognitive functioning (different tests) and presence of confounding factors such as medication and other diseases, are all factors that can influence the results. The outcome in some studies has been conversion to dementia, ${ }^{17} 19$ whereas the outcome in our study as well as in some other studies ${ }^{12}$ was cognitive decline. The difference in the selected outcome and the timing of the sample collection may partially explain differences in the results.

Single measurement of plasma $A \beta$ may not be a suitable marker for $\mathrm{AD}$ due to many confounding factors. The timing of the $A \beta$ measurement in terms of the natural history of $A D$ may be critical. Experimental studies on transgenic animals suggest that plasma $A \beta$ levels decrease at the time when accumulation of $A \beta$ begins in the brains. ${ }^{9}$ It is possible that the increased plasma $A \beta$ concentration is related to the development of $A D$ as suggested by the findings of elevated plasma $A \beta$ levels in $A D$ gene mutation carriers ${ }^{43}$ and in the first-degree relatives of the patients with late-onset $\mathrm{AD} .^{15}$ However, since amyloid pathology in the brain begins years before the appearance of the first symptoms, the possible increase in plasma $A \beta$ may not be detected in the symptomatic individuals. This hypothesis can only be addressed in longitudinal studies. In line with our results, previous studies have suggested that decreasing $A \beta$ levels are associated with cognitive decline, ${ }^{19}{ }^{24}$ and $A \beta 42$ levels were lower in patients diagnosed having $\mathrm{AD}$ than in those with MCI. ${ }^{44}$ Many studies have shown that plasma A $\beta$ levels increase with age, as was found in the cognitively intact subjects in our study. ${ }^{19} 2542$ In one study, the age-related increase was smallest in those subjects who converted to $\mathrm{AD}$ from $\mathrm{MCI}^{25}$ It is possible that age-related changes of plasma levels of $A \beta 40$ and $\mathrm{A} \beta 42$ differ in subjects with $\mathrm{AD}$. In this respect, the $\mathrm{A} \beta 42 / \mathrm{A} \beta 40$ ratio may be a better predictor for $\mathrm{AD}$ than the single markers.

Differences in study cohorts make the comparison between different studies difficult. There are many confounding factors that may influence plasma $A \beta$ levels. Renal dysfunction may increase plasma, since plasma $A \beta$ is excreted through the kidneys. ${ }^{45}$ Many studies have suggested an association between vascular disease and plasma $A \beta$ levels. ${ }^{46-48}$ The levels of plasma homocysteine, a possible marker for vascular disease, correlate positively with plasma $A \beta 40$ and $A \beta 42$ levels. ${ }^{49}$ Previous studies have also suggested that certain drugs may influence plasma $A \beta{ }^{50}$ We found elevated levels of $A \beta 40$ in the subjects who were using ASA and dipyridamole, that is drugs that directly influence platelet function and activation, and subjects who used anticoagulation and antidiabetic drugs, whereas there was no association between the use of NSAIDs or lipid-lowering agents and plasma A $\beta$ levels. The association between ASA and plasma A $\beta 40$ was seen also in subjects without cardiovascular diseases. In line with previous studies, ${ }^{50}{ }^{51}$ no relationship was found between $A \beta$ levels and lipid-lowering agents in previous studies.

Differences in methodology and experimental conditions may also influence results. Erythrocytes and plasma proteins, for example albumin and lipoproteins, bind $A \beta$ and denaturating conditions liberate $A \beta$ into the free pool of plasma. ${ }^{52}$ Also, the different antibodies used in the immunological assays may detect different fractions of $A \beta$. Previous studies suggested that the absolute levels of $A \beta$ vary across different ELISA batches. ${ }^{53}$ We also noticed a difference between absolute levels in 70 samples that were measured twice 4 years apart. Because of these methodological difficulties, the diagnostic value of a single measurement is limited.

The significance of the standardisation of the conditions in storing and handling the samples is reported in a study by Vanderstichele et al. ${ }^{22}$ To better utilise these analyses, the assays used should be commercially available, well standardised and thoroughly validated.

We conclude that plasma $A \beta$ is not a diagnostic marker for $\mathrm{AD}$, but the decreasing levels of $\mathrm{A} \beta 42$ in serial measurements may be associated with cognitive decline and indicate the development of $\mathrm{AD}$.

Funding This study was supported by Health Research Council of the Academy of Finland, EVO grants from the Kuopio University Hospital 5883, 5772720, 5772722 and 5772725, Nordic Centre of Excellence in Neurodegeneration and the Finnish Cultural Foundation's North Savo Regional fund and North Kymenlaakso Regional fund.

Competing interests None. 
Ethics approval Ethics approval was provided by the Kuopio University Hospital Ethical Committee.

Provenance and peer review Not commissioned; not externally peer reviewed.

\section{REFERENCES}

1. Selkoe DJ. Alzheimer's disease: a central role for amyloid. J Neuropathol Exp Neurol 1994;53:438-7.

2. Chen M, Inestrosa NC, Ross GS, et al. Platelets are the primary source of amyloid beta-peptide in human blood. Biochem Biophys Res Commun 1995;213:96-103.

3. Selkoe DJ. Alzheimer's disease: genes, proteins, and therapy. Physiol Rev 2001;81:741-66.

4. Gravina SA, Ho L, Long KE, et al. Amyloid beta Protein (Abeta) in Alzheimer's Disease Brain. J Biol Chem 1995;270:7013-16.

5. Iwatsubo T, Mann DM, Odaka A, et al. Amyloid beta protein (A beta) deposition: A beta 42(43) precedes A beta 40 in Down syndrome. Ann Neurol 1995;37:294-99.

6. Blennow K, Hampel H. CSF markers for incipient Alzheimer's disease. Lancet Neurol 2003:2:605-13.

7. Herukka SK, Helisalmi S, Hallikainen M, et al. CSF Abeta42, Tau and phosphorylated Tau, APOE epsilon 4 allele and $\mathrm{MCl}$ type in progressive MCl. Neurobiol Aging 2007;28:507-14.

8. Dubois B, Feldman $\mathrm{HH}$, Jacova $\mathrm{C}$, et al. Research criteria for the diagnosis of Alzheimer's disease: revising the NINCDS-ADRDA criteria. Lancet Neurol 2007;6:734-46.

9. Kawarabayashi T, Younkin LH, Saido TC, et al. Age-dependent changes in brain, CSF, and plasma amyloid (beta) protein in the Tg2576 transgenic mouse model of Alzheimer's disease. J Neurosci 2001;21:372-81.

10. Ghersi-Egea JF, Gorevic PD, Ghiso J, et al. Fate of cerebrospinal fluid-borne amyloid beta-peptide: rapid clearance into blood and appreciable accumulation by cerebral arteries. J Neurochem 1996;67:880-3

11. Shibata M, Yamada S, Kumar SR, et al. Clearance of Alzheimer's amyloid-ss(1-40) peptide from brain by LDL receptor-related protein-1 at the blood-brain barrier. J Clin Invest 2000;106:1489-99.

12. Graff-Radford NR, Crook JE, Lucas J, et al. Association of low plasma Abeta42/ Abeta40 ratios with increased imminent risk for mild cognitive impairment and Alzheimer Disease. Arch Neurol 2007:64:354-62.

13. Scheuner D, Eckman C, Jensen M, et al. Secreted amyloid beta-protein similar to that in the senile plaques of Alzheimer's disease is increased in vivo by the presenilin 1 and 2 and APP mutations linked to familial Alzheimer's disease. Nat Med 1996;2:864-70

14. Schupf N, Patel B, Pang D, et al. Elevated plasma beta-amyloid peptide Abeta(42) levels, incident dementia, and mortality in down syndrome. Arch Neurol 2007;64:1007-13.

15. Ertekin-Taner N, Younkin LH, Yager DM, et al. Plasma amyloid B protein is elevated in late-onset Alzheimer disease families. Neurology 2008:70:596-606.

16. Mehta PD, Pirttila T, Mehta SP, et al. Plasma and cerebrospinal fluid levels of amyloid beta proteins 1-40 and 1-42 in Alzheimer disease. Arch.Neurol 2000:57:100-5.

17. van Oijen M, Hofman $A$, Soares $H D$, et al. Plasma $A \beta 1-40$ and $A \beta 1-42$ and the risk of dementia: a prospective case-cohort study. Lancet Neurol 2006;5:655-60.

18. Sundelof $\mathbf{J}$, Giedraitis V, Irizarry MC, et al. Plasma beta amyloid and the risk of Alzheimer disease and dementia in elderly men: a prospective, population-based cohort study. Arch Neurol 2008;65:256-63.

19. Mayeux R, Honig LS, Tang MX, et al. Plasma A[beta]40 and A[beta]42 and Alzheimer's disease: relation to age, mortality, and risk. Neurology 2003;61:1185-90.

20. Sobow T, Flirski M, Kloszewska I, et al. Plasma levels of alpha beta peptides are altered in amnestic mild cognitive impairment but not in sporadic Alzheimer's disease. Acta Neurobiol Exp (Wars) 2005;65:117-24.

21. Tamaoka A, Fukushima T, Sawamura N, et al. Amyloid beta protein in plasma from patients with sporadic Alzheimer's disease. J Neurol Sci 1996;141:65-8.

22. Vanderstichele H, Van Kerschaver E, Hesse C, et al. Standardization of measurement of beta-amyloid(1-42) in cerebrospinal fluid and plasma. Amyloid 2000; 7:245-58

23. Irizarry MC. Biomarkers of Alzheimer disease in plasma. NeuroRx 2004;1:226-34

24. Graff-Radford NR, Lucas JA, Petersen RC, et al. Analysis of plasma AB42 as a premorbid biomarker for late onset Alzheimer's disease. Neurobiol Aging 2004; 25(Suppl 2):S354.

25. Blasko I, Jellinger $\mathrm{K}, \mathrm{Kemmler} \mathrm{G}$, et al. Conversion from cognitive health to mild cognitive impairment and Alzheimer's disease: prediction by plasma amyloid beta 42 , medial temporal lobe atrophy and homocysteine. Neurobiol Aging 2008;29:1-11.
26. Schupf N, Tang MX, Fukuyama $\mathrm{H}$, et al. Peripheral Abeta subspecies as risk biomarkers of Alzheimer's disease. Proc Natl Acad Sci U S A 2008;105:14052-57.

27. Hanninen T, Hallikainen M, Tuomainen $S$, et al. Prevalence of mild cognitive impairment: a population-based study in elderly subjects. Acta Neurol Scand 2002; 106:148-54.

28. Tervo S, Kivipelto M, Hanninen $T$, et al. Incidence and risk factors for mild cognitive impairment: a population-based three-year follow-up study of cognitively healthy elderly subjects. Dement Geriatr Cogn Disord 2004;17:196-203.

29. Russel EW. A multiple scoring method for the assessment of complex memory functions. J Cons Clin Psychol 1975;43:800-9.

30. Morris JC, Heyman A, Mohs RC, et al. The Consortium to Establish a Registry for Alzheimer's Disease (CERAD). Part I. Clinical and neuropsychological assessment of Alzheimer's disease. Neurology 1989;39:1159-65.

31. Wechsler D. Wechsler Memory scale-Revised manual. San Antonio, TX: Psychological Corporation 1987.

32. Kluger A, Ferris SH, Golomb J, et al. Neuropsychological prediction of decline to dementia in nondemented elderly. J Geriatr Psychiatry Neurol 1999;12:168-79.

33. Wechsler D. Wechsler adult intelligence scale-revised. Cleveland, $\mathrm{OH}$ : Psychological Corporation, 1981.

34. Kaplan EF, Goodglass H, Wcintraub S. The Boston naming test. Boston, MA: Kaplan \& Goodglass, 1991.

35. Reitan RM. Validity of the Trail Making test as an indicator of organic brain damage Percept Mot Skills 1958;8:271-6.

36. Borkowski JG, Benton AL, Spreen 0. Word fluency and brain damage. Neuropsychologia 1967:5:135-40.

37. Butters N, Granholm E, Salmon DP, et al. Episodic and semantic memory: a comparison of amnesic and demented patients. J Clin Exp Neuropsychol 1987; 9:479-97

38. Folstein MF, Folstein SE, McHugh PR. 'Mini-mental state'. a practical method for grading the cognitive state of patients for the clinician. J Psychiatr Res 1975:12:189-98

39. Tsukamoto K, Watanabe T, Matsushima T, et al. Determination by PCR-RFLP of apo E genotype in a Japanese population. J Lab Clin Med 1993;121:598-602.

40. Assini A, Cammarata S, Vitali A, et al. Plasma levels of amyloid beta-protein 42 are increased in women with mild cognitive impairment. Neurology 2004;63:828-31.

41. Lambert JC, Schraen-Maschke S, Richard F, et al. Association of plasma amyloid beta with risk of dementia: the prospective three-city study. Neurology 2009;73:847-53

42. Lopez $\mathbf{O L}$, Kuller $\mathbf{L H}$, Mehta PD, et al. Plasma amyloid levels and the risk of $A D$ in normal subjects in the cardiovascular health study. Neurology 2008;70:1664-71.

43. Citron M, Westaway D, Xia W, et al. Mutant presenilins of Alzheimer's disease increase production of 42-residue amyloid beta-protein in both transfected cells and transgenic mice. Nat Med 1997;3:67-72.

44. Pesaresi M, Lovati C, Bertora P, et al. Plasma levels of beta-amyloid (1-42) in Alzheimer's disease and mild cognitive impairment. Neurobiology of Aging 2006;27:904-5.

45. Arvanitakis Z, Lucas JA, Younkin LH, et al. Serum creatinine levels correlate with plasma amyloid Beta protein. Alzheimer Dis Assoc Disord 2002;16:187-90.

46. van Dijk EJ, Prins ND, Vermeer SE, et al. Plasma amyloid beta, apolipoprotein E, lacunar infarcts, and white matter lesions. Ann.Neurol 2004:55:570-5.

47. Lee PH, Bang OY, Hwang EM, et al. Circulating beta amyloid protein is elevated in patients with acute ischemic stroke. J Neural Transm 2005;112:1371-9.

48. Gurol ME, Irizarry MC, Smith EE, et al. Plasma beta-amyloid and white matter lesions in $\mathrm{AD}, \mathrm{MCl}$, and cerebral amyloid angiopathy. Neurology 2006;66:23-9.

49. Irizarry MC, Gurol ME, Raju S, et al. Association of homocysteine with plasma amyloid beta protein in aging and neurodegenerative disease. Neurology 2005;65:1402-8

50. Blasko I, Jungwirth $\mathrm{S}$, Jellinger $\mathrm{K}$, et al. Effects of medications on plasma amyloid beta (Abeta) 42: longitudinal data from the VITA cohort. J Psychiatr Res 2008;42:946-55

51. Tokuda T, Tamaoka A, Matsuno S, et al. Plasma levels of amyloid beta proteins did not differ between subjects taking statins and those not taking statins. Ann Neurol 2001;49:546-7.

52. Kuo YM, Kokjohn TA, Kalback W, et al. Amyloid-beta peptides interact with plasma proteins and erythrocytes: implications for their quantitation in plasma. Biochem Biophys Res Commun 2000:268:750-6.

53. Golde TE, Eckman CB, Younkin SG. Biochemical detection of Abeta isoforms: implications for pathogenesis, diagnosis, and treatment of Alzheimer's disease. Biochim Biophys Acta 2000;1502:172-87. 